Check for updates

Cite this: Chem. Sci., 2017, 8, 4347

Received 12th February 2017

Accepted 27th March 2017

DOI: $10.1039 / \mathrm{c} 7 \mathrm{sc00658f}$

rsc.li/chemical-science

\title{
Metalloradical activation of $\alpha$-formyldiazoacetates for the catalytic asymmetric radical cyclopropanation of alkenes $\uparrow$
}

\author{
Xue Xu, ${ }^{\text {b }}$ Yong Wang, (D) ${ }^{a}$ Xin Cui, ${ }^{\text {b }}$ Lukasz Wojtas $^{\mathrm{b}}$ and X. Peter Zhang (D) *ab \\ For the first time, $\boldsymbol{\alpha}$-formyldiazoacetates have been successfully applied for the asymmetric \\ cyclopropanation of alkenes via Co(॥)-based metalloradical catalysis. The cobalt(॥) complex of the $D_{2^{-}}$ \\ symmetric chiral amidoporphyrin [Co(3,5-Dit Bu-ChenPhyrin)] is an effective metalloradical catalyst that \\ can activate $\alpha$-formyldiazoacetates to cyclopropanate both aromatic and aliphatic olefins with varied \\ electronic properties, affording the synthetically useful 1,1-cyclopropaneformylesters in high yields with \\ both high diastereo- and enantioselectivity.
}

\section{Introduction}

Radical reactions have been increasingly exploited as attractive tools in modern organic synthesis as they exhibit a number of unique features, including tolerance of functional groups. ${ }^{1}$ To address the existing challenges such as the control of enantioselectivity, ${ }^{2}$ metalloradical catalysis (MRC) has rendered a fundamentally new approach that enables the catalytic generation of metal-stabilized organic radicals as well as the selective control of their subsequent radical reactions. ${ }^{3,4}$ As stable metalloradicals, cobalt(II) complexes of the $D_{2}$-symmetric chiral amidoporphyrins $\left[\operatorname{Co}\left(D_{2}-\right.\right.$ Por $\left.\left.^{*}\right)\right]$ have emerged as a class of effective catalysts for asymmetric olefin cyclopropanation through a distinct radical process involving the catalytic generation of $\alpha$-metalloalkyl radicals as the key intermediates (Scheme 1: A). ${ }^{5}$ It has been suggested that the unusual capability of $\left[\mathrm{Co}\left(D_{2}\right.\right.$-Por* $\left.)\right]$ in activating acceptor/ acceptor-substituted diazo reagents as well as regulating the reactivity and selectivity of the radical processes is further enhanced by the postulated double hydrogen-bonding interactions between the amide $\mathrm{N}-\mathrm{H}$ donors on the amidoporphyrin ligand and the two acceptors on the C-centered radical moiety (Scheme 1). ${ }^{\text {seg, }, h}$ Considering the demonstrated functional group tolerance of $\mathrm{Co}$ (II)-based metalloradical catalysis (Co(II)-MRC), ${ }^{5 d, e, j-l}$ we were attracted to the possibility of accessing a new type of $\alpha$ metalloalkyl radical bearing both $\alpha$-formyl and $\alpha$-alkoxycarbonyl functionalities from the metalloradical activation of $\alpha$-formyldiazoacetates (FDA). ${ }^{6}$ Despite the fact that free $\alpha$-formylalkyl radicals are scarce and prone to $\mathrm{H}$-atom abstraction because of the

${ }^{a}$ Department of Chemistry, Merkert Chemistry Center, Boston College, Chestnut Hill, Massachusetts 02467, USA. E-mail: peter.zhang@bc.edu

${ }^{b}$ Department of Chemistry, University of South Florida, Tampa, FL 33620, USA

$\dagger$ Electronic supplementary information (ESI) available. CCDC 1532256. For ESI and crystallographic data in CIF or other electronic format see DOI: $10.1039 / \mathrm{c} 7 \mathrm{sc} 00658 \mathrm{f}$ weak aldehydic $\mathrm{C}-\mathrm{H}$ bonds, ${ }^{7}$ we reasoned that this type of $\alpha$-metalloalkyl radical might be accessible on the basis of the combined effects of metal stabilization, double H-bonding interaction, and protection by the well-defined cavity of the ligand system (Scheme 1: A). Assuming that the $\alpha$-formyl- $\alpha$-alkoxycarbonyl- $\alpha$-Co(III)-alkyl radicals (A) are capable of undergoing stereoselective radical addition with olefins, followed by the effective 3-exo-tet radical cyclization $^{8}$ of the corresponding $\gamma$-Co(III)-alkyl radicals (B), we anticipated the potential development of a new catalytic process for the asymmetric synthesis of optically active cyclopropanes bearing both aldehyde and ester functionalities, which would be valuable for stereoselective organic synthesis (Scheme 1). ${ }^{9}$

The catalytic asymmetric cyclopropanation of alkenes with diazo reagents represents the most general approach for the stereoselective synthesis of optically active cyclopropanes. ${ }^{10}$ While a number of diazo reagents have been successfully employed, there is no previous report of a catalytic system that is effective for asymmetric olefin cyclopropanation with $\alpha$-formyldiazoacetates (FDAs). The development of this catalytic process apparently confronts the formidable challenges

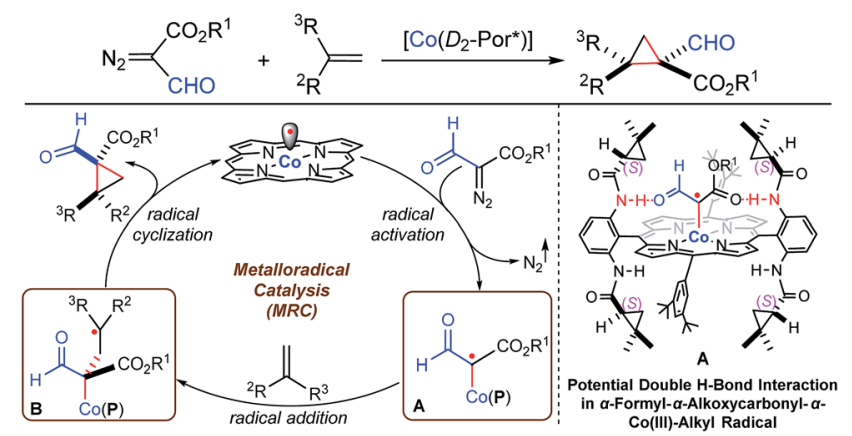

Scheme 1 Working proposal for the radical cyclopropanation of alkenes with FDA via Co(॥)-MRC. 
associated with the inherent low reactivity of the acceptor/ acceptor-substituted diazo reagents and the incompatibility of the aldehyde functionality with existing catalytic systems. ${ }^{11}$ Recently, Fokin and coworkers developed a $\mathrm{Rh}_{2}$-catalyzed system for a highly asymmetric cyclopropanation with $\mathrm{N}$ sulfonyl-1,2,3-triazoles for the production of cyclopropyl imines, which could be subsequently transformed into the corresponding formyl cyclopropane derivatives. ${ }^{12}$ While this offers a valuable alternative for the preparation of optically active formyl cyclopropanes, the direct synthesis via asymmetric cyclopropanation with $\alpha$-formyl diazo reagents is an appealing process that remains to be developed. As a new application of $\mathrm{Co}(\mathrm{II})-\mathrm{MRC}$, we herein wish to report the first catalytic system based on $\left[\mathrm{Co}\left(D_{2}\right.\right.$-Por* $\left.)\right]$ that is highly effective in activating FDA for asymmetric cyclopropanation. This asymmetric radical process is generally applicable for a broad scope of alkenes, offering a direct method for the high-yielding synthesis of 1,1cyclopropaneformylesters with excellent control of the diastereo- and enantioselectivity. The products can be readily transformed into other chiral 1,1-bifunctionalized cyclopropanes and chiral dihydrofurans.

\section{Results and discussion}

Initial experiments were carried out with styrene as the model substrate to examine the suitability of FDA for the catalytic radical cyclopropanation by $\mathrm{Co}(\mathrm{II})$-MRC (Table 1 ). While $\left[\mathrm{Rh}_{2}(\mathrm{OAc})_{4}\right]$ was indeed incompatible (entry 1), [Co(TPP)] only produced trace amounts of the corresponding cyclopropane from ethyl $\alpha$-formyldiazoacetate (EFDA) (entry 2). Remarkably, when the Co(II) complex of the $D_{2 \mathrm{~h}^{-}}$Symmetric achiral amidoporphyrin $[\mathrm{Co}(\mathbf{P 1})]^{13}$ was used as the catalyst, the reaction proceeded successfully to form the desired (E)-1,1cyclopropaneformylester in a $46 \%$ yield (entry 3 ). The dramatic difference in the catalytic activity between [Co(TPP)] and $[\mathrm{Co}(\mathbf{P 1})]$ is in alignment with the hypothesized role of the double H-bonding interaction in activating EFDA and stabilizing the resulting intermediate A (Scheme 1). By switching to $[\mathrm{Co}(\mathbf{P} 2)],{ }^{14}$ the reactivity was further enhanced with the observation of a significant level of enantioselectivity (entry 4). Of the solvents examined, toluene was proven to be the medium of choice (entries 4-8). Lowering the reaction temperature further increased the enantioselectivity, but decreased the yield (entries 8-10). The diastereoselectivity was greatly improved when the bulkier tert-butyl $\alpha$-formyldiazoacetate ( $t$-BFDA) was used, affording cyclopropane 1a in a 78\% yield with 95 : $5 \mathrm{dr}$ and $96 \%$ ee (entry 11). The product yield could be further improved to $84 \%$ by increasing the catalyst loading to $5 \mathrm{~mol} \%$ while maintaining the high level of diastereo- and enantioselectivity (entry 12).

Under the optimized conditions, the scope of this $\mathrm{Co}$ (II)based asymmetric radical cyclopropanation was investigated

Table 1 The catalytic asymmetric cyclopropanation of styrene with FDA ${ }^{a}$

\begin{tabular}{|c|c|c|c|c|c|c|c|}
\hline & & $\begin{array}{l}\mathrm{Ph} \\
1.0 \text { equiv. }\end{array}$ & $\mathrm{N}_{2}=\underbrace{\mathrm{CO}_{2} \mathrm{R}}_{1.2 \text { equiv. }}$ & $\begin{array}{r}\text { catalyst }(2 \mathrm{~mol} \%) \\
\text { solvent; temp; } 24 \mathrm{~h}\end{array}$ & $\begin{array}{l}\mathrm{CO}_{2} \mathrm{R} \\
\left.\mathrm{R}={ }^{t} \mathrm{Bu}\right)\end{array}$ & & \\
\hline Entry & Catalyst & $\mathrm{R}$ & Solvent & Temp. $\left({ }^{\circ} \mathrm{C}\right)$ & Yield $^{b}(\%)$ & $(E):(Z)$ & $\mathrm{ee}^{c}(\%)$ \\
\hline 1 & {$\left[\mathrm{Rh}_{2}(\mathrm{OAc})_{4}\right]$} & Et & DCM & 60 & 0 & - & - \\
\hline 2 & {$[\mathrm{Co}(\mathrm{TPP})]$} & Et & DCM & 60 & $<10^{d}$ & - & - \\
\hline 3 & {$[\mathrm{Co}(\mathbf{P 1})]$} & Et & DCM & 60 & 46 & $84: 16$ & - \\
\hline 4 & {$[\mathrm{Co}(\mathbf{P} 2)]$} & Et & DCM & 60 & 81 & $80: 20$ & 81 \\
\hline 5 & {$[\mathrm{Co}(\mathbf{P} 2)]$} & Et & EtOAc & 60 & 81 & $80: 20$ & 81 \\
\hline 6 & {$[\mathrm{Co}(\mathbf{P} 2)]$} & Et & $\mathrm{PhCl}$ & 60 & 73 & $82: 18$ & 83 \\
\hline 7 & {$[\mathrm{Co}(\mathbf{P} 2)]$} & Et & Hexanes & 60 & 73 & $80: 20$ & 82 \\
\hline 8 & {$[\mathrm{Co}(\mathbf{P} 2)]$} & Et & Toluene & 60 & 86 & $85: 15$ & 86 \\
\hline 9 & {$[\mathrm{Co}(\mathbf{P} 2)]$} & Et & Toluene & 40 & 73 & $86: 14$ & 90 \\
\hline 10 & {$[\mathrm{Co}(\mathbf{P} 2)]$} & Et & Toluene & $\mathrm{RT}$ & 60 & $87: 13$ & 93 \\
\hline 11 & {$[\mathrm{Co}(\mathbf{P} 2)]$} & ${ }^{t} \mathrm{Bu}$ & Toluene & 40 & 78 & $95: 5$ & 96 \\
\hline $12^{e}$ & {$[\mathrm{Co}(\mathbf{P} 2)]$} & ${ }^{t} \mathrm{Bu}$ & Toluene & 40 & 84 & $95: 5$ & 96 \\
\hline
\end{tabular}

\footnotetext{
${ }^{a}$ Carried out in one-portion under $\mathrm{N}_{2}$ with [olefin] $=0.20 \mathrm{M} .{ }^{b}$ Isolated yields. ${ }^{c}$ ee of major $(E)$-diastereomer determined by chiral HPLC.

${ }^{d}$ Determined by ${ }^{1} \mathrm{H}-\mathrm{NMR} .{ }^{e}$ With $5 \mathrm{~mol} \%$ of catalyst for $20 \mathrm{~h}$.
} 
(Table 2). Like styrene, its derivatives bearing substituents with varied electronic and steric properties could be cyclopropanated by $[\mathrm{Co}(\mathbf{P} 2)]$ with $t$-BFDA. For example, $p$ - and $m$-alkyl styrenes were cyclopropanated to formylcyclopropanes $\mathbf{1 b}-\mathbf{1 d}$ in high yields with excellent diastereo- and enantioselectivity (entries 13). Halogenated (entries 4-6) and electron-deficient (entries 7 and 8) styrene derivatives could also undergo high-yielding cyclopropanation, producing 1e-1i with high stereoselectivities. The configurations of the two contiguous chiral centers in $\mathbf{1 h}$ were established as $[1 R, 2 S]$ by X-ray crystal structural analysis (see ESI $\dagger$ ). The cyclopropanation was also suitable for other aromatic olefins as exemplified with 2-naphthalene for near quantitative formation of cyclopropane $\mathbf{1 j}$ (entry 9). In addition, 1,1-disubstituted olefins such as $\alpha$-methylstyrene could also be effectively employed, affording (E)-formylcyclopropane $1 \mathbf{k}$ in a $93 \%$ yield with remarkable control of both the diastereo- and enantioselectivity of the two newlygenerated contiguous all-carbon quaternary stereogenic centers (entry 10). To demonstrate the functional group tolerance of the $\mathrm{Co}$ (II)-based radical cyclopropanation, $m$-formylstyrene could be effectively cyclopropanated to cyclopropane $\mathbf{1 l}$ in a high yield with high diastereo- and enantioselectivity (entry 11). Notably, the two unprotected formyl groups were well

Table 2 The asymmetric cyclopropanation of alkenes with $t$-BFDA by $[\mathrm{Co}(\mathrm{P} 2)]^{a, b, c}$

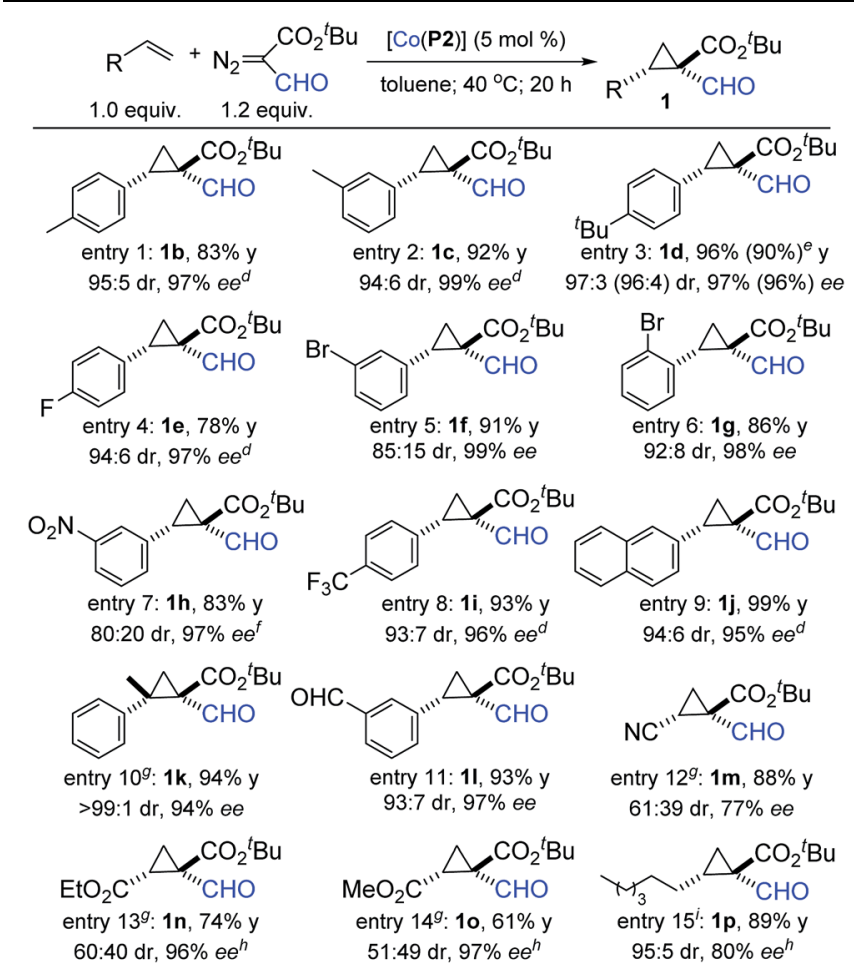

${ }^{a}$ Carried out in one-portion under $\mathrm{N}_{2}$ with [olefin] $=0.20 \mathrm{M} .{ }^{b}$ Isolated yields. ${ }^{c}$ ee of major $(E)$-diastereomer determined by chiral HPLC. ${ }^{d}$ ee determined upon derivatization. ${ }^{e}$ Results in the parentheses were obtained for the reaction performed on a $1.0 \mathrm{mmol}$ scale. ${ }^{f}$ Absolute configuration determined by X-ray diffraction as $[1 R, 2 S] .{ }^{g} 5$ equiv. olefin. ${ }^{h}$ ee determined by chiral GC. ${ }^{i}$ Neat condition. tolerated by the metalloradical system. It is also worth mentioning that the $\mathrm{Co}(\mathrm{II})$-catalyzed cyclopropanation process could be scaled up ten-fold as demonstrated with the highyielding synthesis of the cyclopropane $1 \mathrm{~d}$ on a $1.0 \mathrm{mmol}$ scale without affecting the excellent stereoselectivity (entry 3 ).

The Co(II)-based radical cyclopropanation was further highlighted for its exceptional reactivity toward electron-deficient olefins, which are typically problematic substrates for catalytic systems involving electrophilic metallocarbene intermediates. For example, $[\mathrm{Co}(\mathbf{P 2})]$ could catalyze the $\mathrm{C}=\mathrm{C}$ cyclopropanation of acrylonitrile with $t$-BFDA to form 1,1,2-cyclopropaneformylesternitrile $\mathbf{1 m}$ in a high yield with good enantioselectivity (entry 12), leaving the cyano group untouched. In marked contrast, when treated with $\mathrm{Rh}_{2}$-based catalyst, acrylonitrile was previously shown to react with the $\mathrm{C} \equiv \mathrm{N}$ bond of FDA to form oxazoles. ${ }^{15}$ Other electron-deficient olefins such as ethyl and methyl acrylates could also be cyclopropanated to form the 1,1,2-cyclopropaneformyldiesters $\mathbf{1 n}$ and 10 in good yields with 96\% ee and 97\% ee, respectively, although with diminished control of diastereoselectivity (entries 13 and 14). The presence of three electron-withdrawing groups in the cyclopropanes $\mathbf{1 m}$ 10 renders them highly electrophilic, making them valuable intermediates for synthetic applications. ${ }^{16}$ Furthermore, aliphatic olefins, another class of challenging substrate for asymmetric cyclopropanation, could also be cyclopropanated by $[\mathrm{Co}(\mathbf{P} 2)]$ as exemplified by the high-yielding reaction of 1-octene under neat condition, forming $\mathbf{1 p}$ with high stereoselectivity (entry 15).

As an initial exploration of applications, the formyl unit of the resulting chiral 1,1-cyclopropaneformylesters could be readily converted into other functional groups, forming various cyclopropane derivatives while retaining high enantiopurity. For example, the formyl group in $(E)$-1a could be transformed into a trans-vinyl unit via the Horner-Wadsworth-Emmons reaction, affording $(E)$-1,1-cyclopropanevinylester 2 in a $78 \%$ yield with full retention of both the relative and absolute configurations (eqn (1)). When treated with Bestmann-Ohira reagent, the formyl group in $(E)$-1a could be smoothly converted to a terminal alkyne functionality, resulting in chiral $(E)-1,1$ cyclopropaneethynylester 3 in a 70\% yield without any diminishment of the original stereochemistry (eqn (2)). This transformation provides an alternative way to direct asymmetric cyclopropanation with $\alpha$-ethynyldiazoacetates for chiral 1,1cyclopropaneethynylesters. ${ }^{17}$ It is noted that $\alpha$-ethynyldiazoacetates containing terminal alkyne units seem synthetically inaccessible. While the $[\mathrm{Co}(\mathbf{P} 2)]$-catalyzed cyclopropanation with FDA generally forms $(E)$-cyclopropanes, the $(Z)$-diastereoisomers could be conveniently accessed through the stereospecific epimerization previously reported. ${ }^{5 e}$ As demonstrated with $(E)-\mathbf{1 a}$, treatment with 5 equivalents of $\mathrm{NaI}$ at room temperature resulted in the formation of $(Z)-\mathbf{1 a}$ as the major diastereomer with only partial loss of the original optical purity (eqn (3)). Interestingly, when $(E)$-1g was treated with 10 equivalents of $\mathrm{NaI}$ at an elevated temperature, a ring-expansion involving the formyl group occurred instead, affording 2,3dihydrofuran 4 in a $74 \%$ yield (eqn (4)). In the absence of any 
external chiral induction, the enantiopurity appeared to be largely retained during the rearrangement.

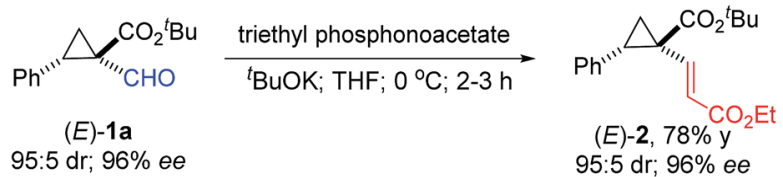

$95: 5 \mathrm{dr} ; 96 \%$ ee 95:5 dr: $96 \%$ ee
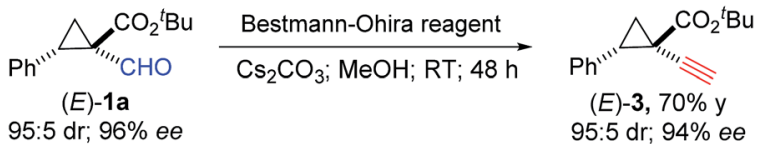

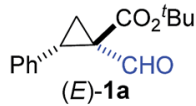

$95: 5 E: Z ; 96 \%$ ee
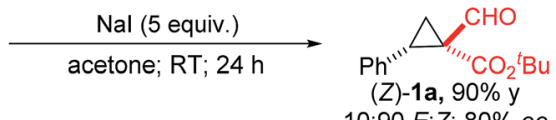

\section{3}

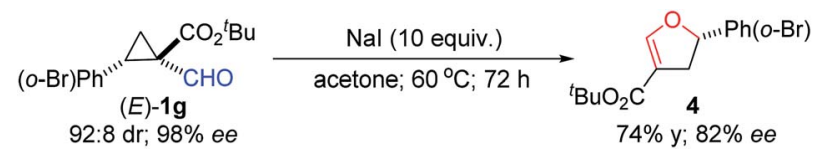

\section{Conclusions}

In summary, we have demonstrated that the metalloradical catalyst $[\mathrm{Co}(\mathbf{P} 2)]$ can effectively activate $\alpha$-formyldiazoacetates (FDAs) for a highly asymmetric olefin cyclopropanation, without affecting the otherwise reactive aldehyde functionality. This represents the first application of $\alpha$-formyldiazo reagents for metal-catalyzed asymmetric cyclopropanation. The Co(II)-based radical cyclopropanation with FDA can be successfully applied to a broad scope of olefin substrates, permitting the direct synthesis of chiral 1,1-cyclopropaneformylesters in high yields with high diastereo- and enantioselectivity. Given that the resulting enantioenriched cyclopropanes contain two contiguous chiral centers in the ring structure, including one allcarbon quaternary stereogenic center bearing both aldehyde and ester functionalities, this new Co(II)-based asymmetric radical cyclopropanation process should find wide applications in stereoselective organic synthesis.

\section{Acknowledgements}

We are grateful for financial support from the NIH (R01GM102554).

\section{References}

1 (a) B. Quiclet-Sire and S. Z. Zard, Pure Appl. Chem., 2011, 83, 519-551; (b) M. H. Shaw, J. Twilton and D. W. C. MacMillan, J. Org. Chem., 2016, 81, 6898-6926; (c) M. Yan, J. C. Lo, or reviews and highlights on Co(II)-MRC, see: (a) A. Studer and D. P. Curran, Angew. Chem., Int. Ed. Engl., 2016, 55, 58-102; (b) H. Pellissier and H. Clavier, Chem. Rev., 2014, 114, 2775-2823; (c) A. I. Olivos Suarez, V. Lyaskovskyy, J. N. Reek, J. I. van der Vlugt and B. de Bruin, Angew. Chem., Int. Ed. Engl., 2013, 52, 12510-12529; (d) L. Degennaro, P. Trinchera and R. Luisi, Chem. Rev., 2014, 114, 7881-7929; (e) H. Lu and X. P. Zhang, Chem. Soc. Rev., 2011, 40, 1899-1909; (f) M. P. Doyle, Angew. Chem., Int. Ed. Engl., 2009, 48, 850-852.

J. T. Edwards and P. S. Baran, J. Am. Chem. Soc., 2016, 138, 12692-12714.

For selected examples of recent approaches to control enantioselectivity of radical reactions, see: (a) Q. M. Kainz, C. D. Matier, A. Bartoszewicz, S. L. Zultanski, J. C. Peters and G. C. Fu, Science, 2016, 351, 681-684; (b) J. L. Jeffrey, J. A. Terrett and D. W. C. MacMillan, Science, 2015, 349, 1532-1536; (c) J. M. Hoyt, V. A. Schmidt, A. M. Tondreau and P. J. Chirik, Science, 2015, 349, 960-963; (d) J. N. Du, K. L. Skubi, D. M. Schultz and T. P. Yoon, Science, 2014, 344, 392-396; (e) N. Funken, F. Mühlhaus and A. Gansäuer, Angew. Chem., Int. Ed., 2016, 55, 12030-12034.

4 For reviews and examples of $\mathrm{Ti}(\mathrm{III})$-based MRC, see: $(a)$ A. Gansauer, S. Hildebrandt, E. Vogelsang and R. A. Flowers Ii, Dalton Trans., 2016, 45, 448-452; (b) W. A. Nugent and T. V. RajanBabu, J. Am. Chem. Soc., 1988, 110, 8561-8562; (c) A. Gansäuer, B. Rinker, M. Pierobon, S. Grimme, M. Gerenkamp and C. Mück-Lichtenfeld, Angew. Chem., Int. Ed., 2003, 42, 3687-3690; (d) A. Gansäuer, A. Fleckhaus, M. A. Lafont, A. Okkel, K. Kotsis, A. Anoop and F. Neese, J. Am. Chem. Soc., 2009, 131, 16989-16999; (e) A. Gansäuer, S. Hildebrandt, A. Michelmann, T. Dahmen, D. von Laufenberg, C. Kube, G. D. Fianu and R. A. Flowers, Angew. Chem., Int. Ed., 2015, 54, 7003-7006.

5 For detailed studies on the involvement of $\alpha$-Co(III)-alkyl radical intermediates (also known as $\mathrm{Co}$ (III)-carbene radicals) for catalytic cyclopropanation, see: (a) H. J. Lu, W. I. Dzik, X. Xu, L. Wojtas, B. de Bruin and X. P. Zhang, J. Am. Chem. Soc., 2011, 133, 8518-8521; (b) J. L. Belof, C. R. Cioce, X. Xu, X. P. Zhang, B. Space and H. L. Woodcock, Organometallics, 2011, 30, 2739-2746; (c) W. I. Dzik, X. Xu, X. P. Zhang, J. N. H. Reek and B. de Bruin, J. Am. Chem. Soc., 2010, 132, 10891-10902; For selected examples of asymmetric radical cyclopropanation and related processes via Co(II)-MRC, see: (d) Y. Wang, X. Wen, X. Cui, L. Wojtas and X. P. Zhang, J. Am. Chem. Soc., 2017, 139, 1049-1052; (e) X. Xu, S. F. Zhu, X. Cui, L. Wojtas and X. P. Zhang, Angew. Chem., Int. Ed., 2013, 52, 11857-11861; (f) X. Xu, H. J. Lu, J. V. Ruppel, X. Cui, S. L. de Mesa, L. Wojtas and X. P. Zhang, J. Am. Chem. Soc., 2011, 133, 15292-15295; (g) S. F. Zhu, X. Xu, J. A. Perman and X. P. Zhang, J. Am. Chem. Soc., 2010, 132, 12796-12799; (h) S. F. Zhu, J. A. Perman and X. P. Zhang, Angew. Chem., Int. Ed., 2008, 47, 8460-8463; (i) S. F. Zhu, J. V. Ruppel, H. J. Lu, L. Wojtas and X. P. Zhang, J. Am. Chem. Soc., 2008, 130, 5042-5043; (j) Y. Chen, J. V. Ruppel and 
X. P. Zhang, J. Am. Chem. Soc., 2007, 129, 12074-12075; (k) X. Cui, X. Xu, L. Wojtas, M. M. Kim and X. P. Zhang, J. Am. Chem. Soc., 2012, 134, 19981-19984; (l) X. Cui, X. Xu, H. J. Lu, S. F. Zhu, L. Wojtas and X. P. Zhang, J. Am. Chem. Soc., 2011, 133, 3304-3307.

6 FDAs are a class of commonly used $\alpha$-formyldiazo reagent due to their easy access and relative stability: (a) O. Sezer and O. Anac, Helv. Chim. Acta, 1994, 77, 2323-2334; (b) O. Sezer, K. Dabak, O. Anac and A. Akar, Helv. Chim. Acta, 1997, 80, 960-965.

7 G. G. Melikyan, in Organic Reactions, John Wiley \& Sons, Inc., 1997, vol. 49, pp. 427-675.

8 For select examples of 3-exo-tet radical cyclization, see: $(a)$ A. M. del Hoyo and M. García Suero, Eur. J. Org. Chem., 2017, DOI: 10.1002/ejoc.201601604; (b) A. M. del Hoyo, A. G. Herraiz and M. G. Suero, Angew. Chem., Int. Ed., 2017, 56, 1610-1613; (c) T. Ohkita, Y. Tsuchiya and H. Togo, Tetrahedron, 2008, 64, 7247-7251; (d) D. P. Curran and A. E. Gabarda, Tetrahedron, 1999, 55, 3327-3336.

9 (a) J. W. Bode and S. S. Sohn, J. Am. Chem. Soc., 2007, 129, 13798-13799; (b) G. Q. Li, L. X. Dai and S. L. You, Org. Lett., 2009, 11, 1623-1625; (c) H. Lv, J. M. Mo, X. Q. Fang and Y. R. Chi, Org. Lett., 2011, 13, 5366-5369; (d) S. S. Sohn and J. W. Bode, Angew. Chem., Int. Ed., 2006, 45, 60216024; (e) X. Y. Tang, Y. Wei and M. Shi, Org. Lett., 2010, 12, 5120-5123; ( $f$ ) S. Kalidindi, W. B. Jeong, A. Schall, R. Bandichhor, B. Nosse and O. Reiser, Angew. Chem., Int. $E d$. 2007, 46, 6361-6363; $(g)$ B. M. Trost, Y. Hu and D. B. Horne, J. Am. Chem. Soc., 2007, 129, 11781-11790; (h) J. D. White, W. H. C. Martin, C. Lincoln and J. Yang, Org. Lett., 2007, 9, 3481-3483.

10 (a) D. Intrieri, D. M. Carminati and E. Gallo, Dalton Trans., 2016, 45, 15746-15761; (b) G. Bartoli, G. Bencivenni and
R. Dalpozzo, Synthesis, 2014, 46, 979-1029; (c) S. Zhu, X. Cui and X. P. Zhang, Eur. J. Inorg. Chem., 2012, 2012, 430-434; (d) H. M. L. Davies and E. G. Antoulinakis, in Organic Reactions, John Wiley \& Sons, Inc., 2001, vol. 57, p. 1; (e) H. Lebel, J.-F. Marcoux, C. Molinaro and A. B. Charette, Chem. Rev., 2003, 103, 977-1050; (f) M. P. Doyle and D. C. Forbes, Chem. Rev., 1998, 98, 911-935. 11 E. Wenkert, T. P. Ananthanarayan, V. F. Ferreira, M. G. Hoffmann and H. Kim, J. Org. Chem., 1990, 55, 4975-4976.

12 (a) N. Grimster, L. Zhang and V. V. Fokin, J. Am. Chem. Soc., 2010, 132, 2510-2511; (b) S. Chuprakov, S. W. Kwok, L. Zhang, L. Lercher and V. V. Fokin, J. Am. Chem. Soc., 2009, 131, 18034-18035.

13 J. V. Ruppel, J. E. Jones, C. A. Huff, R. M. Kamble, Y. Chen and X. P. Zhang, Org. Lett., 2008, 10, 1995-1998.

14 Y. Chen, K. B. Fields and X. P. Zhang, J. Am. Chem. Soc., 2004, 126, 14718-14719.

15 (a) R. D. Connell, M. Tebbe, A. R. Gangloff, P. Helquist and B. Akermark, Tetrahedron, 1993, 49, 5445-5459; (b) R. D. Connell, M. Tebbe, P. Helquist and B. Akermark, Tetrahedron Lett., 1991, 32, 17-20; (c) J. Linder, T. P. Garner, H. E. L. Williams, M. S. Searle and C. J. Moody, J. Am. Chem. Soc., 2011, 133, 1044-1051.

16 (a) F. Gnad and O. Reiser, Chem. Rev., 2003, 103, 1603-1623; (b) C. Cativiela and M. D. Diaz-de-Villegas, Tetrahedron: Asymmetry, 2000, 11, 645-732; (c) S. Danishefsky, Acc. Chem. Res., 1979, 12, 66-72; (d) H. N. C. Wong, M. Y. Hon, C. W. Tse, Y. C. Yip, J. Tanko and T. Hudlicky, Chem. Rev., 1989, 89, 165-198.

17 H. M. L. Davies and T. A. Boebel, Tetrahedron Lett., 2000, 41, 8189-8192. 